\title{
Linguistic Challenges Lived by University Students in Bogotá in the Development of Academic Literacy*
}

\section{Retos linguísticos de los estudiantes universitarios en el desarrollo de la escritura académica}

\author{
Sanjay Nanwani \\ English Teacher \\ English Department, Universidad Externado de Colombia \\ Specialization in Bilingualism, Universidad El Bosque, \\ E-mail: nanwani77@yahoo.com
}

\begin{abstract}
The focus of this paper is on the challenges that Colombian university students live when developing academic writing in English as a foreign language. At the macro level, it points to the importance of a theoretically informed understanding of teaching practices in ELT; at the micro level it intends to sensitize ELT practitioners, and particularly academic writing instructors, on the diverse challenges students - particularly non-native learners - experience when appropriating a largely unknown discourse upon entry to the university. Excerpts from participants in a two-year study intertwine with a theoretical discussion on academic writing are presented.
\end{abstract}

Key words: academic writing, context-specific instruction, culturally sensitive instruction, linear rhetorical structure.

\section{Resumen}

El enfoque principal de este artículo se basa en los retos a los cuales se enfrentan los estudiantes universitarios colombianos a la hora de desarrollar la escritura académica en inglés como lengua extranjera. A un nivel macro, se señala la importancia de una amplia comprensión teórica de prácticas de enseñanza; a un nivel micro pretende sensibilizar a profesores y maestros, especialmente a aquellos de redacción académica, de los diversos retos a los que los estudiantes, sobre todo no nativos, se enfrentan para apropiarse de un discurso mayoritariamente desconocido cuando entran a la universidad. Se incluyen extractos de participantes en un estudio llevado a cabo en dos años, los cuales se entrelazan con una discusión teórica de la escriyura académica.

Palabras Claves: escritura académica, enseñanza contextualizada, enseñanza culturalmente sensible, estructura retórica lineal.

\section{Introduction}

The central theme of this paper is academic writing and the challenges that it poses for students. The focus is on Colombian university students. Theory and practice converge: excerpts of participants in a study that I have been conducting for the past two years illustrate some of the theoretical perspectives presented. I explain why I have chosen this theme, its relevance to my educational context, and I present a theoretical description of how academic literacies are understood.

* Received 04-02-09 / Accepted 24-08-09 
However, first, I find it relevant to provide a three-page description of the context and background of my educational setting, which includes what sprouted my interest in academic literacies. This interest stems from my teaching experiences at a private university in Bogotá, where through my students' written production, discussion and observation, I detected the difficulties they experienced in writing academically in English. Myles (2002), among many other researchers, acknowledges the challenge that L2 writing, and specifically academic writing, poses: "Academic writing requires conscious effort and much practice in composing, developing and analyzing ideas. Students writing in a second language are also faced with social and cognitive challenges related to second language acquisition" (p.1). However, I wanted to gain a deeper understanding of these difficulties: what was the range of difficulties that emerged? How did these relate to each other? What caused these difficulties? How were they manifested? Why were they difficulties? What effect did they have in the development of academic literacy? Were they challenges that were cognitively based, culturally based, socio-culturally based, psychologically based, or other?

The academic writing courses that I taught at one of the private universities in Colombia were content based, and the fact that they focused on North American culture did not facilitate the learning process of academic writing: in a questionnaire aimed at acquainting myself with student interests and needs, there was a generalized response towards a lack of interest in writing on aspects of North American culture. A comment that particularly resonates in my mind is that of an industrial design student who wrote: "I personally don't care for the (North) American culture." According to Myles, "Learners' attitudes, motivations, and goals can explain why some L2 writers perform better than others"
(2002, p. 5). In effect, at least learners' attitudes and motivations towards the main theme (i.e. North American culture) through which academic writing was going to be taught, had not been seriously considered; the curriculum was defined by a small number of faculty members, following a top-down approach. This neglect was not going to facilitate the process of developing academic writing instruction - based not only on a foreign writing style, but also on a foreign culture towards which students were not particularly interested.

In essence, not only had learners' interests been blatantly disregarded but our approach to academic writing instruction was based on a limited understanding of the challenges that students encountered in their writing processes. This is not to say that we (i.e. the faculty at the university) did not have a general awareness of what students found particularly difficult as they learnt to acquire an academic discourse. However, complementing this awareness with a greater understanding of the internal challenges of students in the process of writing - those that were not explicitly detectable in students' artifacts - would potentially lead towards an informed, contextually-situated and focused instruction.

Additionally, while we were "teaching" students to think critically - given that we all appeared to conceive academic writing as inevitably inextricably linked to critical thinking we had not reflected on a number of fundamental issues: (a) How did we understand writing: as a process, product, or both? (b) If our teaching instruction included tasks such as outlines (a product that is fabricated in the pre-writing stage), why was our assessment exclusively based on the final product? (c) What were the perceptions of students regarding one, academic writing, and two, our assessment criteria? (d) To what degree did the way we assess the final product facilitate or hinder students' developmental writing process? (e) How motivating was it for students that the 
15-week academic writing course was based on North American culture?

As far as the academic writing model at the core of our instruction, we were employing an Anglo-American style to academic writing, characterized by a linear rhetorical structure and principles (e.g. coherence, cohesion, concision, textual simplicity) interpreted from a Western lens. This model is described as "...both necessary and desirable for the non-native users of English to learn to construct text according to paradigms commonly found in Anglo-American writing if they wish to participate in and contribute to the pool of scientific and technological knowledge" (Swales and Feak, 1994 in Kachru, 1999, p.7)

However, unconsciously, we were basing the development of academic writing on a limited view of literacy - essentially a single view of academic literacy, based on a foreign model, which has become the standard norm in academic writing instruction. At a time when globalization forces are prevalent, and the discussion of democratizing education is at the forefront, instructors of second language writing will, in all likelihood, have to espouse a view of literacy development that encompasses "various social practices that inform academic discourses" (McKay, 1993, p. 70) - versus focusing on one single discourse that is largely Anglo-American in essence. McKay (1993) points out that acknowledging the plurality of discourses - similarly to acknowledging the plurality of literacies, in my view - will inevitably alter power structures and relationships in the classroom:

Power in many classrooms resides to a great extent in the teachers. Freire (1970) terms such an approach a banking model of education, in which the role of the teacher is to transmit to students a particular body of knowledge. In many L2 composition classes, this body of knowledge includes the social conventions that govern writing in a Western academic discourse setting. Certainly such a transmission model of education is ideal if the goal of writing classes is to initiate students into the academic discourse of Western universities. But if the goal is not for a one-way initiation but rather for an understanding and validation of other intellectual traditions that can inform academic discourses, relationships in L2 classrooms will need to change (1993, p. 76-77).

Instructional objectives must therefore be clearly defined. How these are approached pedagogically must be an additional concern.

In essence, instructional paradigms are being transferred from centre countries to periphery countries. Guadilla (1987) explains the inherent risk of transferring paradigms:

"Cuando el concepto ha sido elaborado en un contexto determinado y es utilizado en otro contexto diferente, existe el riesgo de que no se tomen en cuenta las especificidades culturales de este último..." (p. 14).

"When the concept has been developed in a specific context and is employed in a different context, there is the risk of not taking into account cultural specificities of the latter..." (translation mine).

Cultural specificities of learners and specific contextual characteristics therefore must be considered in instructional models.

\section{Justification and Relevance to Educational Context}

In exploring the challenges Colombian university students in a private university face when developing academic writing based on the Anglo-American style (henceforth AAS), my study has partly been aimed at gaining a deeper understanding of the cultural specificities of 
learners and the specific contextual characteristics in which this development takes place. From a general perspective, globalisation trends and increasing communication that is technologically mediated, transcending geographical borders, have led second language writing to become "an important if not dominant focus of work in second language studies" (Silva and Brice, 2004, p. 7). Silva and Brice posit, "the study of second language writing has become a legitimate area of inquiry in its own right" (2004, p. 7).

More concretely, however, and plainly stated, what justifies expanding my knowledge of academic writing instruction through this paper is that I happen to continue teaching academic writing in Colombia - this time to English language instructors in private schools pursuing higher level studies in a specialization in Bilingualism. One might have imagined that English language instructors would have been academically literate in English. However, they appear to grapple with similar difficulties as those of my undergraduate students. I therefore firmly believe that exploring the challenges that Colombian students (both at an undergraduate and graduate level) experience when developing academic literacy based on the AAS, will lead me to approach academic writing instruction from a contextually situated perspective - a requirement (and a moral obligation) that I owe to my Colombian students, to my profession, as well as to myself.

Similarly, at the macro level, it is my hope that it will serve to sensitize the ELT community on the sheer challenges embedded in the development of academic writing, and consequently encourage ELT practitioners to approach instruction from "the perspective of sociocultural situatedness" (Lin, Wang, Akamatsu, Riazi, 2004, p. 216) - or in my words, from a contextually situated perspective.
As far as its relevance to my specific educational context - but not limited to it - academic writing based on the AAS is a genre that expands the literacies of students in Colombia and elsewhere. Additionally, it is a type of literacy that students are required to adopt when pursuing higher level studies (undergraduate and graduate studies). In fact, it is an exit requirement to graduate from undergraduate programmes (e.g. at Universidad de Los Andes in Bogotá students must show English language proficiency by taking the TOEFL or the IELTS); it is also an entry requirement in Masters programmes (e.g. at Universidad Distrital, in the Masters programme in Applied Linguistics to TEFL, students are required to show English language proficiency by taking the TOEFL).

Academic writing based on the AAS is not only limited to an instructional model that is employed to help students acquire an academic discourse, but is also a benchmark used to evaluate English language proficiency of native and non-native students. Irrespective of the economic implications, this comes at a pedagogical cost, where, I am afraid, students' cognitive and socio-cultural make-up is not taken into account.

\section{Theory and Practice Converge}

This section presents theoretical constructs and simultaneously is complemented with excerpts from participants in a two year study that I conducted. Hence, a logical point of departure seems to be to address (a) what is academic writing, and (b) what is academic writing based on the AAS. This includes a discussion of the multiple variables that are part of this genre, and that potentially enable students to become academically literate.

\section{What is Academic Writing?}

Plainly stated, academic writing is a mode of communication that is community specific: it 
is a mode that is written largely by members of the academic community, for members in the academic community. Its particular features, or rules, distinguish it from other types of writing genres. It is these features or rules that I focus on in this section, in order to understand the multiple variables that converge to make academic writing what it is.

\section{Grammar and Morphology}

First, as Scarcella and Rumberger posit, academic writing requires greater grammatical and morphological precision (2000). This academic written discourse is in sharp contrast from communication through speech: the former written discourse is essentially a solitary activity - particularly the composing stage, where ideas are put on paper - reducing the possibility of direct social interaction and feedback with interlocutors. In contrast, speech allows for repetition, backtracking and expansion, all partly conditioned to the interlocutor's reaction to the spoken word, and its level of clarity. These linguistic elements are absent in writing, forcing the writer to keep channels of communication open through conscious selection of vocabulary, sentence structure, and linking devices - all of which contribute to successfully conveying "messages".

Due to the fact that academic discourse and speech are essentially different in nature, it is no surprise to find students whose language skills evidence a classic disconnection between a strong oral proficiency and weaker academic writing abilities, or vice versa. To illustrate, Generation 1.5 students - that is, those who arrived in the USA at a young age (Park, 1999; Roberge, 2002), and who have traits of both first and second generation immigrants (Harklau, Siegal \& Losey, 1999) - are an example of the former, many of whom are placed in separate sections of a particular level: the class is divided in two, with students who are perceived to be more advanced in terms of writing and reading placed in one section, while those perceived to have weaker writing and reading skills placed in another section. This shows how writing skills condition academic placement. This in turn has serious implications regarding how these students are viewed by academia, often perceived as weaker students compared to the average student. Additionally, this has potentially serious effects in terms of identity development: how a student perceives him/herself as a person and as a student.

Research studies, however, have confirmed the importance of having a language base - that is, a sufficiently ample vocabulary base and knowledge of grammatical and syntactic structures - in order to appropriately develop academic literacies. Myles posits, "...language proficiency and competence underlies the ability to write in the L2 in a fundamental way. Therefore, L2 writing instructors should take into account both strategy development and language skill development when working with students" (2002, p. 1). Simpson points to the same concern: "Writers need to have enough language and general intellectual skills to generate and organize ideas and put those ideas into coherent, logically ordered, intelligible sentences, paragraphs, and essays" (1998, p.9).

Regarding language proficiency, one of the participants in my study wrote:

There are other errors that I haven't overcome yet and what I want with this analysis is to reflect upon them, in order to continue evolving as a writer. One of these errors is the absence of a rich and adequate vocabulary. I consider it is a content difficulty, because if you don't use the correct vocabulary the essay's content become poor and weak; maybe your idea could be really interesting, but if you don't know to use the precise vocabulary to express it, it could loss its interest (From participant $\mathrm{P} 3$, in essay 4, lines 17-22). 
Another participant wrote:

I had too much problems with awkward phrases or words because as my native language is not English, I tend to write in English as I do in Spanish. In several occasions I tend to translate the phrases directly from the Spanish, reason for which these do not make the same sense on having read them in English (From participant $\mathrm{C1}$, in essay 4, lines 75-78).

A third participant referred to "language barriers":

It is clear that due to the fact that English is not my first language, I have weaknesses in the use of several words, prepositions and some expressions that might sound awkward in English but are pretty normal in Spanish. That would be what I call "language barriers" (From participant N5, in essay 4, lines 13-16).

Referring to the writing problems that Spanish speakers face in the United States, Plata (1995) refers to a multiplicity of factors that include the effects of transfer and interference from the Spanish language. This multiplicity of factors has to be addressed in the development of academic literacies.

\section{Register}

Halliday's concept of register explains "the relationship between text and context and suggests that the situations which determine how text meanings are interpreted differ according to their field, tenor and mode" (Hyland, 2002, p. 1415). Though I shall not embark on an extensive discussion of field, tenor and mode, these elements are "configured in texts" and "embodied in the concept of genre" (Hyland, 2002, p. 16). According to Hyland (2002), Halliday stays away from the term "genre", though he acknowledges it through his concern of the relationship between form, function and context. Hence, to become academically literate, students require knowledge of, and practice in, specific lexical, grammatical, stylistic and rhetorical conventions that are community-specific. In this particular case these pertain to the academic community.

\section{Cognitive Demand}

Developing grammatical and morphological precision while adopting the appropriate register is cognitively demanding. This cognitive demand is actually magnified when also incorporating appropriate rhetorical structure, knowledge of the audience (readers), critical thinking and a number of principles such as coherence, concision, cohesiveness and simplicity. Thus, the cognitive demand does not only emerge from the number of elements that learners of academic literacies ought to take into account, but the complexity embedded in each one of these elements. Zuñiga and Macías (2006), for example, make reference to the complexity of summarizing, among other activities:

We as teachers often notice the difficulties
our students face at an undergraduate
foreign language teaching program when
writing academic papers, especially when
they are asked to summarize, paraphrase,
cite and acknowledge sources, and
use other specific devices relevant to
academic writing (p. 312).

This complements Rincón (1997), who studied how teachers conceived and understood what a summary was, and found that these ranged widely. Hence, how teachers convey to learners what a summary is would also inevitably vary. Subsequently it is only logical that when students actually apply their understanding of what a summary is when producing one would also differ greatly. This demands language instructors, and writing instructors, to have a solid, theoreticallybased conceptual knowledge pertaining to their teaching practices.

One of the participants in the study referred to the challenge of thinking critically: 
Another issue I can observe about my cognitive mistakes is that I tend to generalize the ideas, not letting the reader get to the point of the essay. Maybe I have a tendency to be radical in my ideas by not permitting the reader to think if there exists a second opinion. The following phrase shows a clear example of this mistake: 'Every aspect of Colombia's life organization is based on the idea of collectivism.' (From participant C1, in essay 4, lines 85-89).

The participant above understood that critical thinking goes beyond generalizations of a black and white nature: it requires thinking critically by analyzing the "gray shades" and adopting balanced views - what Facione (1998) describes as being "open-minded, flexible, fair-minded in evaluation..." (in Pineda, 2003, p.10).

Regarding the challenge of conveying a point in a simple manner - what academic writing textbooks generally interpret as conveying a point in the least possible words - another participant wrote:

A second error I need to overcome in my process is the use of redundant phrases. The problem is that sometimes I have too many things to add and I try to say them all. The result is a redundant phrase with a lot of words, that doesn't express what I really want to say, and only contributes to confuse the reader. (From participant P3, in essay 4, lines 28-3122).

Similarly, another participant alluded to the same challenge:

I am usually too wordy and somehow redundant. I could say that this weakness is typical in a Spanish-Colombian writer because we tend, and sometimes we are even urged, to repeat and describe the same idea, several times, but in different words. That is why, then, the essays end up being clearly redundant and wordy." (From participant N5, in essay 4, lines 9-13).
It is interesting that the participant above makes reference to the fact that Colombians are "urged to repeat and describe the same idea, several times, but in different words." Uribe - a Colombian social scientist - appears to endorse this idea:

“...también se asigna a los colombianos el democraterismo expresado en su fuerte tendencia hacia el formalismo, el electorerismo y la retórica o verbalismo interminable, que generalmente no conduce a los hechos (in Rojas Trujillo, 1994, p. 205).

\section{What is Academic Writing Based on the AAS?}

Thus, based on the discussion above, academic writing requires greater grammatical and morphological accuracy, a formal tone or register, appropriate rhetorical structure, knowledge of the audience (readers), critical thinking and a number of principles such as coherence, concision, cohesiveness and simplicity. Though acquiring an academic discourse poses difficulties for both native and non-native speakers given that it is a new literacy that students typically encounter upon entry to university (Carlino, 2008), "This is made more difficult for students writing in English as a second language by their lack of familiarity with the conventions and expectations of academic writing in English medium universities" (Ballard \& Clanchy, 1997, in Paltridge, 2004). Dong (1997) states that academic writing:

... involves learning a new set of academic rules and learning how to play by these rules. Often, these rules change from discipline to discipline, and the audience and the purpose of writing vary according to each writing context. For non-native students, the mismatch of writing difficulties and expectations operating in their home countries compound their writing difficulties (p. 10). 
However, what specifically distinguishes academic writing based on the AAS (from academic writing in general) is what the subsequent discussion focuses on: linear rhetorical structure; reader-based prose; principles established by centre countries.

\section{Linear Rhetorical Structure}

As far back as in 1966 Kaplan proposed five models of paragraph organization based on five linguistic groups. This was based on the notion that speakers of different languages use different techniques to present information; differ in their manner of establishing relationships among ideas; reveal centrality of one idea versus another distinctly. Though Kaplan's proposition may not hold true after 42 years, it does open the discussion relating to the fact that different writers have their own ways of developing a theme - and that this development may not necessarily be linear, as academic writing based on the AAS advocates. One of the participants in the study wrote:

"... at the beginning of the semester I realized I did not like to follow such specific structure to write an essay, because as everybody, I have my own way of developing a subject..." (From participant C1, in essay 4, lines 69-70).

At another point she referred to the rhetorical rigidity of academic writing based on the AAS, which according to her stifled her creativity:

I also think that this Paradigm follows a very rigid structure that limits writers to make essays in a more flexible way. Perhaps in my case it was difficult to adapt to a marked structure in which I could not be flexible about creating ideas as I can trough the Colombian Paradigm. (From participant $\mathrm{C} 1$, in essay 4 , lines 108-111).

Similarly, a second participant, referring to content, wrote: "The content of the essay must be consequent and not dynamic. The essay must be limited by the essay question." (From participant DC8, in essay 4 , lines 54-55). A third participant echoed the same idea: the fact that the anglo-american structure is rigid compared to its "spanish equivalent", (From participant JM7, in essay 4, line 48) and the fact that "I (she) cannot enhance the content of my (her) texts..." (From participant JM7, in essay 4, line 50). How to bridge the gap between producing a linear rhetorical pattern while "creating ideas" and "enhancing text" (to borrow the words of participants in the study) represents a major challenge for L2 academic writing instructors.

In sum, I do endorse Grabe and Kaplan's proposition:

...different cultures have different rhetorical preferences for the organization of written text... Contrastive rhetoric preferences not only shape written text in distinct languages and cultures, but tend to manifest themselves consistently, if subtly, in the writing of students learning a second language (Grabe \& Kaplan, 1996, p.197, in Canagarajah, 2003, p. 64).

Through interaction with participants, and through analysis of artefacts, the study confirmed this proposition.

\section{Reader-Based Prose}

Academic writing based on the AAS requires students to develop what Kern calls "readerly sensitivity" (2000). This is true of any genre, but in academic writing based on the AAS, the writer's burden is greater than in certain Eastern contexts: for example, whereas in the West prose is typically reader-based (i.e. text is constructed with the reader in mind, and conveying the textual messages is in great measure the responsibility of the writer), in Japan prose is typically writerbased: decoding the meaning of the text is in great measure the responsibility of the reader. This is 
not limited to an east-west dichotomy: Maurenen (1992, in Connor, 1996) conducted a study where she concluded that English academic prose was writer responsible (ie. reader-based), and Finnish academic prose was reader-responsible (writer-based). She asserted that this was due to the fact that Finnish students at school are taught in their L1 writing to address an intelligent, knowledgeable, and patient reader (in Connor, 1996).

What emerges from the preceding discussion is that audiences are conceived in different ways depending partly on writers' cultural make-up as well as on the writing instruction received in their respective L1. However, learners have to overcome the challenge of producing and textually presenting meaning, not "in a completely idiosyncratic 'personal' fashion but within socially-determined parameters or constraints" (Kern, 2000, p. 183).

In the study I conducted, as participants reflected and wrote on their processes while developing an academic literacy, one of them showed an increasing awareness of her audience. Here she was specifically referring to the value of reading, and how it helped form "a mental organized structure":

Reading is the solution too. It helps you to make a mental organized structure that you are going to have present in the moment that you are prepared to write; it teaches you to write in a clear and easy way for the reader... it is not only to select perfectly what you are going to wrote, but also, to think how you are going to write it, it means, to organize the sequence of the ideas in order to present the content in a smoothly way, using appropriate transition signals. (From participant P3, in essay 4, lines 34-36 and 39-42).

\section{Principles established by Centre Countries}

Academic writing based on the AAS is different from academic writing due to the fact that a number of elements (or principles) are interpreted from Western lenses. Thus, coherence - which based on the AAS is broadly understood as having the quality of being "easily understood by the reader" - has multiple cultural interpretations. To illustrate this, Matalene (1985, in Connor, 1996) showed "in sample essays written by Chinese ESL students in China that arguments are often delayed, include narration, and use statements that seem unconnected in the eyes of the Western reader. To the Western reader Chinese rhetoric lacks argumentative coherence because of its reliance on appeals to history, tradition, and authority and its frequent reference to historical and religious texts as well as proverbs" (Connor, 1996, p. 38).

\section{Pedagogical Recommendations}

Given the multiplicity of challenges that English academic writing poses for students, five specific steps are suggested here to implement transformation in academic writing instruction: First, instructors should not lose sight of the fact that writing is a process and as such, should provide students with assistance in the different developmental stages. For example, in the prewriting stage, instructors can focus on how ideas are generated, or how an outline is designed. In the composing stage, the initial focus can be on individual sentences such as topic, supporting or concluding sentences, to later focus on writing different types of paragraphs, before embarking on essay writing. This implies that evaluation should not be solely based on the final product (i.e. the essay) but on the products composed at the multiple stages leading towards a final product (i.e. an outline, an introduction, a body paragraph).

Secondly, instructors should adopt the role of facilitators, and not "authorities or fact dispensers" (Johns, 1997, p. 9, in Correa, 2009, p. 106). Thirdly, instructors ought to provide 
students with ample exposure to distinct genres, focusing on how different genres function: how they convey their purpose. This would help to convey the idea that there is no single way of composing an academic writing text, but multiple ways of doing so, in multiple academic voices. This assumes first, that different academic disciplines have their own set of discipline-specific writing conventions, and secondly, that reading is a complementary skill to writing, and students ought to develop their academic reading skills as they develop their academic writing skills.

Fourthly, academic writing instruction should not be exclusively viewed as a subject in the university, but more as a life-time writing activity that provides the opportunity to engage in a discussion with the larger academic community, both inside and outside the university. This subsumes that students are in fact part of the academic community, even if they are acquainting themselves with academic writing conventions.

Fifth, regarding affective challenges, instructors ought to provide ample doses of positive feedback to students, in order to combat feelings of anxiety or awkwardness. This implies that mistakes ought to be considered opportunities towards becoming competent academic writers.

\section{Concluding Remarks}

Becoming academically literate is a complex feat for native and non-native students. My concern, however, primarily focuses on the challenges of non-native speakers of English, and at this particular point in time specifically of Colombian students. Maurenen (1992, in Connor, 1996) pointed to the inherent cultural influences embedded in the development of academic literacies:

"It can therefore be assumed that two sets of values are simultaneously at work in the writing of a scientific report: those common to the academic community and those held in esteem in the writer's national culture" (1992, p. 239).

What perturbs me is whether the sets of values held by non-native writers are taken into account by academia at large or not, and what implications this has on the developmental processes of acquiring academic literacies and students' chances of succeeding in this learning. I am afraid that, even in the 21 st century, we continue to perpetuate discriminatory practices in ESL and EFL.

It is in the wake of these discriminatory practices in the ELT field at large, and specifically in Colombia as well as other so called periphery nations, where academic writing instruction is taught based on foreign paradigms, that I subscribe to a paradigm shift along the one advocated by Lin, Wang, Akamatsu, and Riazi:

“... from doing TESOL to doing TEGCOM (Teaching English for Glocalized Communication" (2004, p. 198). The term glocal combines "global" and "local". It is related to Japanese "dochakuka", from "dochaku" which means "living on one's own land" - and it refers to the agricultural principle of adapting one's farming techniques to local conditions. It is also employed in the business field in Japan, and refers to global localization, a global perspective adapted to local conditions (Robertson, 1995).

This paradigm shift is based on problematizing the colonial self-other dichotomy - one that the term "TESOL" embodies in reference to teacher and learner: "It implicitly positions the Angloteacher as self and the learner in a life trajectory of forever being the Other, and thus continuing the colonial story line of Friday - the 'slave boy' resigned to the destiny of forever trying to approximate the 'master's language' but never legitimately recognized as having achieved it" (de 
Certeau, 1984, p. 155, in Lin, Wang, Akamatsu, and Riazi (2004).

Who our students are, where they come from, and hence their cultural traditions, cannot be taken lightly in ELT and, more specifically, in academic writing instruction. Cultural traditions encompass a wide array of themes, and exert their own influence in the learning process. Among other aspects, these cultural influences partly require what Myles, referring to Spanish-speaking writers, calls a cognitive exchange from learners' L1 to the target language: "Spanish-speaking writers must undergo the task of cognitively exchanging the style of the Spanish language for that of English" (2002, p. 8). Part of the challenge that this cognitive exchange demands stems from the fact that "Learners cannot simply shake off their own culture and step into another" (Byram E Morgan,1994, p. 3, in Hinkel, 1999, p. 7).

On a more practical note, I am not "flirting with interesting ideas and rhetorical moves" (to borrow Lin, Wang, Akamatsu, and Riazi's words, p.219, 2004); instead I firmly subscribe to the view of these researchers to explore alternative discourses - and I may add textualities - in an attempt "...to give legitimacy to local knowledge, to destabilize and rework ideologies that underlie current disciplinary discourses and knowledge production practices" (2004, p. 219).

In essence, according to Lin, Wang, Akamatsu, and Riazi, (2004) the paradigm shift from doing TESOL (Teaching English to Speakers of Other Languages) to doing TEGCOM (Teaching English for Glocalized Communication), requires a series of central research goals: (a) a deeper understanding of diverse local pedagogical practices and beliefs that are socioculturally based; (b) a deeper understanding of issues relating to "agency, identity, ownership, appropriation, resistance, and English language learning, teaching, and use in diverse sociocultural contexts" (2004, p.218); (c) a deeper understanding of various cross-cultural encounters in a range of sociocultural settings.

In order to attain these goals Lin, Wang, Akamatsu, and Riazi (2004) propose possible directions: first, decentralizing the production of disciplinary knowledge and discourse from English speaking countries to a diversity of sociocultural settings worldwide. This would be aimed at legitimizing and valuing local knowledge and discourses produced in settings beyond the traditional English-speaking countries. Second, "To study the issues of agency, identity, ownership, appropriation, resistance, and English learning, teaching and use in diverse sociocultural settings" (2004, p. 219), which point to the need of drawing on the wide array of anthropological and interpretive research methodologies. To exemplify, they refer to research studies in the literacy field, which have heavily relied on anthropological and sociological methods (Street, 1995, 2001, being an example, in Lin, Wang, Akamatsu, and Riazi, 2004).

On a concluding note, a paradigm shift such as the one proposed here demands sheer hard work, a solid theoretical and practical knowledge base, and a burning desire to embrace democratic principles (Nanwani, 2009). Additionally, it may involve clashes and conflict with certain segments in the broader ELT field, who hold their own set of interests. Nevertheless, I believe that increasing research on academic writing instruction conducted in different parts of the globe will inevitably contribute to knowledge production that is socioculturally situated, leading to culturally sensitive instructional approaches at the institutional and classroom level. If this production is directed strategically and aimed principally at benefitting our students at large, it will inevitably alter the status quo, transforming the ELT field and positioning it in what Lin, Wang, Akamatsu, and Riazi call "the postmodern, multipolar, gloc alized world” (2004, p. 219). 


\section{References}

Canagarajah, S. (1999). Resisting linguistic imperialism in English teaching. UK: Oxford University Press

Carlino, P. (2008). ¿Qué nos dicen hoy las investigaciones internacionales sobre la escritura en la universidad? Presentation given at REDLEES, Universidad Pontíficia Javeriana, Bogotá, on 19th September, 2008.

Connor, U. (1996). Contrastive rhetoric. UK: Cambridge University Press

Correa, D. Exploring academic writing and voice in ESL writing. Ikala, Vol. 14, number 21 (January - April 2009)

Dong, Y.R. (1997). Supervising international students requires cultural sensitivity. The Scientist, 11. Sept. 29th.

Freire, P. (1970). Pedagogy of the oppressed. New York: Continuun Publishing

Grabe, W. \& Kaplan, R. (1996). Theory and practice of writing: an applied linguistic perspective. New York, USA: Longman

Guadilla García, C. (1987). Producción y transferencia de paradigmas teóricos en la investigación socioeducativa. Venezuela: Fondo Editorial Tropykos

Harklau, L., Siegal, M. \& Losey, K. (1999). Linguistically diverse students and college writing: what is equitable and appropriate? In Generation 1.5 meets college composition. Mahwah, NJ: Lawrence Erlbaum Associates

Hinkel, E. (1999). Culture in second language teaching and learning. UK: Cambridge University Press

Hyland, k. (2002). Teaching and researching writing . UK: Pearson Education

Kachru, Y. (1999). Culture in second laguage teaching and learning. UK: Cambridge University Press

Kaplan, R. (1966). Cultural thought patterns in intercultural education. Language Learning, 16 (1), p. 1-20

Kern, R. (2000). Literacy and language teaching . UK: Oxford University Press

Lin A., Wang W., Akamatsu N, Riazi M., (2004). International TESOL professionals and teaching English for globalized communication (TEGCOM) in Reclaiming the local in language policy and practice. (Edited by Suresh Canagarajah). USA: Routledge
McKay, S.L. (1993). Examining L2 composition ideology: a look at literacy. Journal of Second Language Writing 2, number 1, p. 65-81.

Myles, J. (2002). Second language writing and research: The writing process and error analysis in student texts. Retrieved in September 2008 from eric.ed.gov/ ERICWebPortal/recordDetail?accno=EJ653951

Nanwani, S. (2009). Academic writing instruction based on the Anglo-American paradigm in Colombia: Implications and risks. In ASOCOPI Newsletter, March 2009. Bogotá, Colombia.

Paltridge, B. (2004). Academic writing. UK: Cambridge University Press

Park, K. (1999). "I really do feel I'm 1.5" The construction of self and community by young Korean Americans. Amerasia Journal, 25(1) 139-163.

Pineda, C. B. (2003). Searching for improved EFL classroom environments: the role of critical thinking-related tasks. Colciencias. Bogota, Colombia: Universidad Externado de Colombia

Plata, M. (1995). Success of Hispanic college students on a writing examination. Journal of Educational Issue of Language Minority Students. Retrieved in December 2008 from www.ncela.gwu.edu/pubs/jeilms/vol15/success.htm

Rincón Bonilla, G. (1997). “Tarea: hacer un resumen. ¿Y los maestros saben hacerlo?" In Entre la lectura y la escritura, de Guillermo Bustamante Zamudio y Fabio Jurado Valencia. Santafé de Bogotá: Magisterio, p.p. 45 - 83.

Roberge, M. (2003). California's Generation 1.5 immigrants: what experiences, characteristics, and needs do they bring to our English classes? Presented at TESOL Convention, Baltimore, MD, 2003.

Robertson, R. (1995). Glocalization: Time - space and homogeneity - heteogeneity. In Lin A., Wang W., Akamatsu N, Riazi M., (2004). International TESOL professionals and teaching English for globalized communication (TEGCOM) in Reclaiming the local in language policy and practice. (Edited by Suresh Canagarajah). USA: Routledge

Rojas Trujillo, G. (1994). Proyecto de vida del colombiano. Bogotá: Instituto Auto-Realización

Scarcella, R. \& Rumberger, S. (2000). Academic English. Linguistic Minority Research Institute Newsletter, 1, 1-2. University of California, Santa Barbara. 
Silva, T. \& Brice, C. (2004). Research in teaching writing. Annual Review of Applied Linguistics. UK: Cambridge University Press

Simpson, J.M. (1998). Research writing in a foreign language. Retrieved in April 2008 from draft.eca.state. gov./forum/vols/vol36/no2/p34.htm

Street, B. (1995). Social literacies: Critical approaches to literacy in development, ethnography and education. London: Longman
Swales, J. and Feak, C. (1994). Academic writing for graduate students. Ann Arbor: The University of Michigan Press

Zuñiga, G. \& Macías (2006). Refining students' academic writing skills in an undergraduate foreign language teaching program. Ikala, Vol. 11, Number 17 